\title{
Heterogeneous Integration of Uni-Travelling-Carrier Photodiodes using Micro-Transfer-Printing on a Silicon-Nitride Platform
}

\author{
Dennis Maes ${ }^{1,2}$, Gunther Roelkens ${ }^{1}$, Mohammed Zaknoune ${ }^{2}$, Camiel Op de Beeck ${ }^{1}$, Stijn Poelman ${ }^{1}$, \\ Maximilien Billet ${ }^{1}$, Muhammad Muneeb ${ }^{1}$, Sam Lemey ${ }^{1}$, Emilien Peytavit ${ }^{2}$, Bart Kuyken ${ }^{1}$ \\ 1. Department of Information Technology (INTEC), Ghent University - imec, Technologiepark-Zwijnaarde, 9052 Ghent, Belgium \\ 2. Institute of Electronics, Microelectronics and Nanotechnology (IEMN), Université de Lille, 59652 Villeneuve d'Ascq, France
}

High-speed photodiodes often compromise responsivity in exchange for a reduced footprint. However, using waveguide photodiodes circumvents this limitation [1]. We combine uni-travelling-carrier photodiodes (UTC PDs) on a silicon nitride ( $\mathrm{SiN}$ ) photonic platform to achieve both high responsivity and high speed detectors. The SiNplatform has excellent properties such as low-loss waveguides and does not suffer from two-foton absorption at high optical power. A high responsivity is obtained through evanescent coupling of waveguide UTC photodiodes to $\mathrm{SiN}$ waveguides while still maintaining a small footprint.

The devices are integrated using the micro-tansfer-printing $(\mu \mathrm{TP})$ technology for hybrid integration of different material platforms [2]. First, photodiode chiplets are made in an InP/InGaAs-technology using a standard fabrication flow. The epitaxial layer stack is adapted from [3] and includes a $500 \mathrm{~nm}$ thick sacrificial InAlAs release layer. This material is used for its excellent selective underetching properties [4]. Figure 1a summarizes the processing steps to create a waveguide-coupled UTC PD. (i) Photodiodes are made on the source wafer. (ii) The InAlAs release layer is anisotropically etched using a hard mask. (iii) A new SiN layer is deposited and patterned to create tethers to the InP-substrate. The device is under-etched (isotropic) to create a suspended coupon. (iv) The coupon is transfer-printed on a SiN target chip. (v) Vias are etched and metal connections are made.

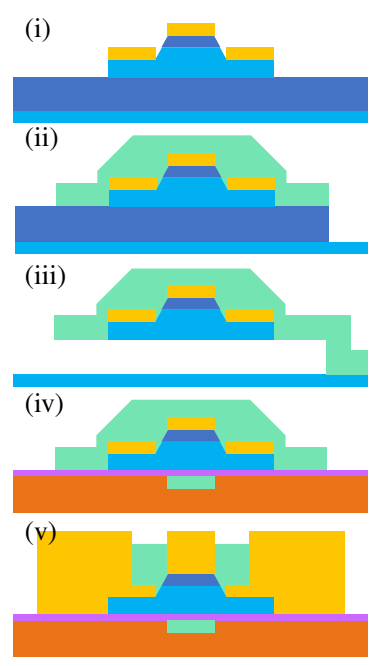

(a)

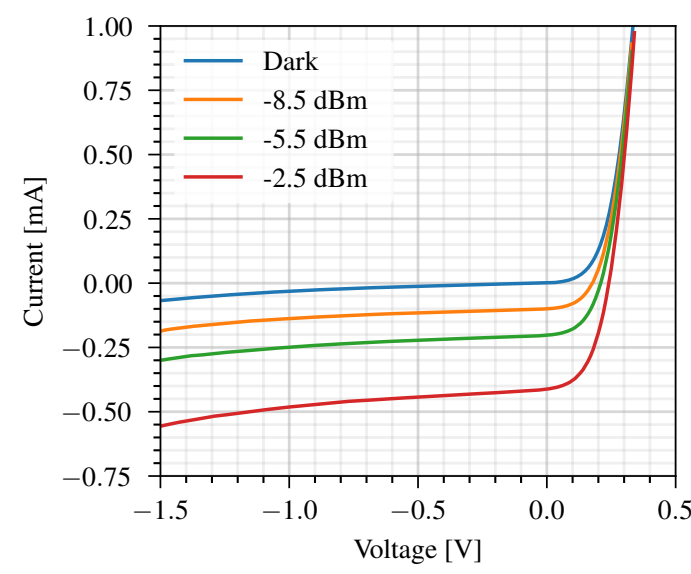

(b)

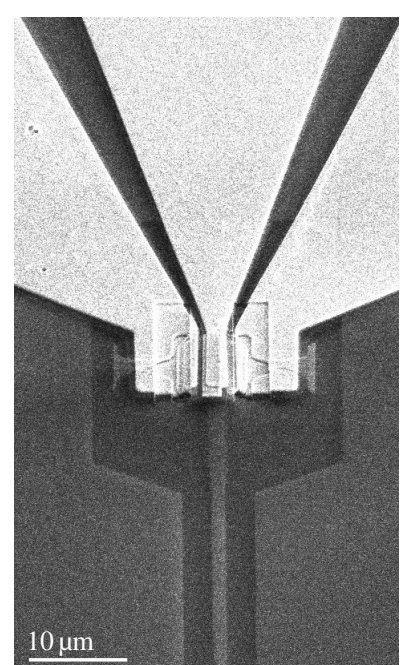

(c)

Fig. 1 (a) Fabrication steps, (b) IV-curves for different incident on-chip powers, and (c) SEM-image of a $2 \mu \mathrm{m} \times 10 \mu \mathrm{m}$ waveguide-coupled UTC PD.

The waveguide-coupled PDs show a responsivity of $0.80 \mathrm{~A} / \mathrm{W}$ for a bias voltage of $-1 \mathrm{~V}$, illuminated at $1550 \mathrm{~nm}$. This corresponds to an external quantum efficiency of $65 \%$. We believe this can be further increased for longer devices or by incorporating a reflection-reducing design in the InP subcollector. The IV-characteristic for a PD with an active area of $2 \mu \mathrm{m} \times 10 \mu \mathrm{m}$ is shown in Figure 1b. High dark currents of 10-20 $\mu \mathrm{A}$ and 20-50 $\mu \mathrm{A}$, at respectively $-0.5 \mathrm{~V}$ and $-1.0 \mathrm{~V}$ biasing, are thought to be a result of surface leakage currents, and are currently being investigated and remedied. Given the small surface area of $20 \mu \mathrm{m}^{2}$ and the average measured series resistance of $30 \Omega$, a high intrinsic bandwidth is expected. This will be verified using RF photoresponse measurements in the near future.

\section{References}

[1] Q. Yu, J. Gao, N. Ye, B. Chen, K. Sun, L. Xie, K. Srinivasan, M. Zervas, G. Navickaite, M. Geiselmann, and A. Beling, "Heterogeneous photodiodes on silicon nitride waveguides", Opt. Express 28, 14824 (2020).

[2] J. Zhang, G. Muliuk, J. Juvert, S. Kumari, J. Goyvaerts, B. Haq, C. Op de Beeck, B. Kuyken, G. Morthier, D. Van Thourhout, R. Baets, G. Lepage, P. Verheyen, J. Van Campenhout, A. Gocalinska, J. O'Callaghan, E. Pelucchi, K. Thomas, B. Corbett, A. J. Trindade, and G. Roelkens, "III-V-on-Si photonic integrated circuits realized using micro-transfer-printing", APL Photonics 4, 110803 (2019).

[3] P. Latzel, F. Pavanello, M. Billet, S. Bretin, A. Beck, M. Vanwolleghem, C. Coinon, X. Wallart, E. Peytavit, G. Ducournau, M. Zaknoune, and J. F. Lampin, "Generation of mW Level in the 300-GHz Band Using Resonant-Cavity-Enhanced Unitraveling Carrier Photodiodes", IEEE Trans. Terahertz Sci. Technol. 7, 800-807 (2017).

[4] J. O'Callaghan, R. Loi, E. E. Mura, B. Roycroft, A. J. Trindade, K. Thomas, A. Gocalinska, E. Pelucchi, J. Zhang, G. Roelkens, C. A. Bower, and B. Corbett, "Comparison of InGaAs and InAlAs sacrificial layers for release of InP-based devices", Opt. Mater. Express 7, 4408 (2017). 